\title{
Novo regime fiscal frente à garantia constitucional de financiamento adequado das políticas públicas de saúde
}

New tax regime in face of constitutional guarantee of adequate financing of public health politics

Nuevo sistema de gastos bajo a garantía de financiación adecuada de las políticas públicas de salud

Lucas Bevilacqua $^{1}$

Fabiana Federico Soares ${ }^{2}$ Júlia Maria Tomás dos Santos ${ }^{3}$

\section{Resumo}

Objetivos: analisar a constitucionalidade da Emenda Constitucional (EC) nำ 95/2016, em especial, cotejando os pisos de aplicação mínima nas ações e serviços públicos de saúde frente às disposições constitucionais garantidoras de financiamento adequado. Especificamente, foram confrontadas as projeções de financiamento do Sistema Único de Saúde (SUS) em face do princípio de vedação ao retrocesso dos direitos sociais. Metodologia: foram realizadas pesquisas teóricas e análises documentais, com base na revisão da literatura e dos dispositivos legais pertinentes, aos quais se agregou a dados empíricos, de maneira a observar indiretamente o fenômeno analisado, através do procedimento técnico da revisão documental. Resultados: a EC no 95/2016 afronta as diretrizes constitucionais da integralidade e universalidade que regem o SUS, já que tende a agravar o déficit de financiamento do Sistema, impedindo o oferecimento adequado e progressivo de ações e serviços públicos de saúde (ASPS) para a população. Discussão: o novo regime fiscal instituído pela Emenda deve viger por duas décadas, valendo até 2036. O discurso oficial argumentava pela necessidade de um novo sistema de despesas públicas, sob a tônica da limitação de gastos e investimentos públicos, sobretudo nos bens e serviços sociais, como medida capaz de retomar o crescimento da economia. Conclusões: os limites de gastos público previstos na EC n 95/2016 agravam a inefetividade do direito à saúde e afrontam premissa constitucional de garantia de financiamento adequado e progressivo das ASPS, subvertendo a lógica de instrumentalidade dos orçamentos e dos recursos públicos em nome da austeridade fiscal. Para além disso, afronta o princípio da vedação ao retrocesso ao impor uma regressividade ao custeio do Sistema.

Palavras-chave: Direito à saúde. Direitos socioeconômicos. Financiamento da assistência à saúde. Responsabilidade financeira.

\footnotetext{
1 Doutor em Direito Econômico, Financeiro e Tributário, Universidade de São Paulo (USP), São Paulo, SP, Brasil; professor, Programa de Pós-graduação em Direito e Políticas Públicas, Universidade Federal de Goiás, Goiânia, Goiás, Brasil. https://orcid.org/0000-0002-4357-8481.E-mail: lucas.bevilacqua@gmail.com

2 Mestranda em Direito e Políticas Públicas, Universidade Federal de Goiás, Goiânia, Goiás, Brasil; juíza de Direito, Tribunal de Justiça do Estado de Goiás, Quirinópolis, Goiás, Brasil. https://orcid.org/0000-0003-0531-9507. E-mail: ffsoares@tjgo.jus.br

3 Mestranda em Direito e Políticas Públicas, Universidade Federal de Goiás, Goiânia, Goiás, Brasil; advogada, Goiânia, Goiás, Brasil. https://orcid.org/0000-0003-4866-1572. E-mail: juliaa.t@hotmail.com
} 


\section{Abstract}

Objectives: to analyze the constitutionality of the Constitutional Amendment n. 95/2016, focusing especially on the minimum standard of public investments on health care provisions, in light of the constitutional norms that impose its adequate financing, by confronting the financing projections of the Brazilian Unified Health System (SUS) with the non-regression clause on social rights. Methodology: theoretical research and documentary analysis were made, based on literature and corresponding legal norms review, alongside with empirical data, so as to indirectly observe the analyzed phenomenon, through the technical procedure of documentary review. Results: the Constitutional Amendment n. 95/2016 transgresses the guidelines of integrality and universality, which rules the Brazilian Unified Health System (SUS) as it tends to increase the System's financing deficit, which prevents the population from having access to adequate and progressive public health care provisions. Discussion: the new fiscal regime implemented by the Amendment will go on for two decades, until 2036. Official discourse pleas the need for a new public expenditure system, stressed by the limitation of public expenses and investments mostly on social services and provisions, as a way of achieving economy growth. Conclusions: public expenditure limits established by the Constitutional Amendment n. 95/2016 increases the ineffectiveness of the right to health and violates the constitutional premise of guaranteeing adequate and progressive financing for public health care provisions, subverting the instrumental aspect of public budgets and resources for the sake of fiscal austerity. Besides, it violates the non regression clause of social rights, as it imposes a regression on the financing instruments to the System's.

Keywords: Right to health. Socioeconomic rights. Healthcare financing. Financial accountability.

\section{Resumen}

Objetivos: analizar la constitucionalidad de la Enmienda Constitucional n. 95/2016, cotejándose especialmente los límites mínimos de aplicación en las acciones y servicios de la salud pública (ASPS) frente a las disposiciones constitucionales que garantizan el funcionamiento del Sistema Único de Salud (SUS) y al principio de no retroceso de los derechos sociales. Metodología: se realizaron investigaciones teóricas y análisis documentales, teniendo por base la revisión de la literatura y de las disposiciones legales pertinentes, lo que se agregó a datos empíricos, para observarse indirectamente el fenómeno analizado, a través del procedimiento técnico de revisión documental. Resultados: la Enmienda Constitucional n. 95/2016 afronta a las directivas constitucionales de integralidad y universalidad, que rigen el SUS, pues tiende a agravar el déficit de financiación del sistema, lo que impide la oferta adecuada y progresiva de ASPS a la población. Discusión: el nuevo régimen fiscal instituído por la Enmienda deve vigorar por dos décadas, hasta el 2036. El discurso oficial argumentaba acerca de la necesidad de un nuevo sistema de gastos públicos, bajo la tónica de la limitación de los gastos e inversiones públicas, especialmente en lo que toca a los bienes y servicios sociales, en cuanto medida capaz de retomar el crecimiento de la economía. Conclusiones: los límites a los gastos públicos previstos por la Enmienda Constitucional n. 95/2016 agravan la inefectividad del derecho a la salud y afrontan la premisa constitucional de garantía de financiación adecuada y progresiva de las ASPS, subvirtiendo la lógica instrumental de los presupuestos y recursos públicos, en nombre de la austeridad fiscal. Más allá, afronta al principio de no retroceso, al imponer regresividad a la financiación del Sistema.

Palabras clave: Derecho a la salud. Derechos socioeconómicos. Financiación de la atención de la salud. Rendición de cuentas financieras. 


\section{Introdução}

A Constituição da República Federativa do Brasil de 1988 (CRFB) (1), além de prever o direito à saúde, atentando para os dispêndios inerentes à sua efetivação, instrumentalizou o respectivo custeio. Há, portanto, um plexo de normas constitucionais de captação e ministração de verbas públicas que se atrela às ações e aos serviços públicos de saúde rumo à universalização. Essas normas ganham ênfase quando contrapostas a guinadas de políticas fiscais tomadas pelos governantes, sobretudo se considerado o desenho do federalismo fiscal brasileiro, o pacto assimétrico de financiamento e a repartição de competências materiais.

A Emenda Constitucional (EC) № 95 de 2016 (2) estabelece um novo regime fiscal que congela os gastos públicos primários por duas décadas $e$, no que se refere ao financiamento da saúde, estabelece piso durante o mesmo período, cujo valor passa a ser atualizado nominalmente apenas pela inflação, desgarrado de qualquer indexador proporcional ao crescimento das receitas arrecadadas, ou mesmo do crescimento da demanda por prestações de saúde. Coloca-se em evidência as novas balizas estabelecidas para o dispêndio público federal em área tão importante à dignidade da pessoa humana, cuja política pública garantidora tem sede constitucional e se informa pela integralidade e pela universalidade.

Paralelamente, esse novo regime fiscal da saúde sobreleva o histórico subfinanciamento do Sistema Único de Saúde (SUS) - apesar de avanços importantes, mas insuficientes rumo à cobertura universal de saúde, desde sua previsão inicial na CRFB.

Trata-se de tema sensível e, no intuito de contribuir com o debate, pretende-se com este artigo analisar a constitucionalidade da EC no 95/2016, tendo como fio condutor o cotejo entre o dever de financiamento adequado do SUS e o piso constitucional de gastos em ações e serviços públicos de saúde (ASPS). Busca, outrossim, refinar o debate, a partir das projeções dos efeitos da EC no 95/2016 em face do princípio de vedação ao retrocesso dos direitos sociais.

\section{Metodologia}

Para empreender uma análise qualitativa adequada da (in)constitucionalidade do regime fiscal da saúde imposto pela $E C$ n 95/2016, conjugou-se a análise documental e revisão da literatura. 
A análise documental teve como base os dispositivos da CRFB, atinentes ao financiamento da saúde, bem como as EC nำ 95/2016 e ํำ 86/2015. Em legislação ordinária, foi objeto de análise o Decreto n 591 de 1992, que internalizou o Pacto Internacional sobre Direitos Econômicos, Sociais e Culturais e a Resolução no 611, de 2018, do Conselho Nacional de Saúde.

$\mathrm{Na}$ jurisprudência, foram analisadas as seguintes ações: Medida Cautelar na Ação Direta de Inconstitucionalidade nº 4.048, Recurso Extraordinário no 27.1286/RS, Ação Direta de Inconstitucionalidade ํㅜ 5.595 e Ação Direta de Inconstitucionalidade ํㅜ 6.129, a partir dos documentos disponibilizados no sítio oficial do Supremo Tribunal Federal (STF).

A seleção da base de dados legal (lato sensu) e jurisprudencial se deu por meio do critério da pertinência temática com o tema garantia constitucional de financiamento adequado do direito à saúde.

A revisão da literatura, que se deu entre maio de 2019 e janeiro de 2020, passou por obras e estudos - teóricos e empíricos - que se inserissem em uma ou mais dessas grandes áreas: direito constitucional, direito à saúde e direito financeiro. A partir daí, afunilou-se a base de dados sob a ótica do financiamento do direito à saúde, em especial, aqueles que abordaram a EC ํㅜ 95/2016.

A junção de todos esses elementos permitiu a construção de uma análise dialéticoargumentativa sobre o problema identificado, análise que denota, hoje, especial pertinência, quando o Supremo Tribunal Federal (STF) cuida de analisar Ações Diretas de Inconstitucionalidade (ADI) relativas à $E C$ no 95/2016.

\section{Resultados e discussão}

O novo regime fiscal instituído pela Emenda deve viger por duas décadas, valendo até 2036. O discurso oficial argumentava pela necessidade de um novo regime de despesas públicas, sob a tônica da limitação de gastos e investimentos públicos, sobretudo nos bens e serviços sociais, como medida capaz de retomar o crescimento da economia.

Todavia, a análise levada a efeito permitiu concluir que a EC nº 95/2016 afronta as diretrizes constitucionais da integralidade e universalidade que regem o SUS, já que impõe um congelamento de despesas que, além de não implicar na manutenção montante gasto com saúde nos mesmos patamares de 2016, imporá uma regressividade ao custeio do SUS em função da crescente demanda e decrescente volume de recursos investidos. 
Esse cenário tende a agravar quadro histórico de financiamento deficitário do SUS, impedindo que as ASPS sejam oferecidas à população em termos adequados.

\section{Enfoque: Direito Financeiro-constitucional}

O constitucionalismo moderno aponta para nova incumbência das constituições. Muito além de tão somente cuidar da estruturação orgânica do Estado, às constituições é delegado o trato de matérias que interessam à sociedade, como o implemento de direitos fundamentais, em vista mesmo da constitucionalização de diversos temas, principalmente a partir da segunda metade do século XX.

Esse constitucionalismo permite que novos ordenamentos jurídicos surjam já constitucionalizados e a partir de uma característica especial, qual seja, a existência de uma Carta Maior com disposições compromissórias e dirigentes, nos planos vertical e horizontal das relações sociais. Portanto, a Constituição é fundamento ético-político da sociedade e, ao mesmo tempo, é fundamento de validade do ordenamento, consubstanciadora da própria atividade político-estatal. (3).

O Estado, para tanto, vale-se de ações e instrumentos variados, a fim de legitimar a sua própria existência, passando a dispor sobre políticas públicas, bem como tudo quanto o que lhe permita o custeio, leia-se atividade financeira (4).

Assim, com vistas à promoção do bem-estar geral, e a partir do momento em que as finanças públicas ganham mais relevo, a análise da atividade financeira do Estado deve ser cotejada segundo o fio da balança constitucional, especialmente no que se refere à arrecadação e aos gastos públicos.

Em vista da relevância da constitucionalização do direito financeiro, sobressalta o orçamento público como instrumento de efetivação de direitos fundamentais.

A lei orçamentária é considerada uma das leis materialmente mais importantes do ordenamento jurídico, pois é neste dispositivo legal que se externa o resultado da ponderação de princípios, determinando, a partir daí as prioridades dos gastos. É ali também que se concretiza a justiça social ao escolher de quem tirar e a quem dar riquezas materiais.

O Ministro Carlos Ayres Britto, por ocasião do julgamento da ADI 4.048, afirmou incisivamente que o orçamento é "a lei materialmente mais importante do ordenamento jurídico logo abaixo da Constituição" (5). 
Diante disso, o orçamento constitucional, ou seja, os limites constitucionais de arrecadação e gastos públicos se ligam ao núcleo da ideia de Estado democrático de direito que se propõe a fazer a justiça social, uma vez que, além de materialmente importante, o sistema constitucional de finanças públicas é formalmente direito fundamental, uma vez inserto no corpo da Constituição.

Nesse sentido, o planejamento financeiro estatal ganha corpo e ares constitucionais sobretudo a partir do surgimento dos direitos de cunho prestacional, levando-se em conta que é a partir do dispêndio de recursos que se efetivam direitos prestacionais.

Igualmente importante é o liame entre o direito financeiro e as normas constitucionais, metodologicamente considerados. A expressão zona secante, que trata da imbricação entre os assuntos financeiro e constitucional, denota esse ponto de convergência. Dentre seus aspectos relevantes, destaca-se o que se refere aos princípios constitucionais da justiça no gasto e na arrecadação. Confira-se:

A zona secante vem justamente a delimitar o que deixa de ser matéria essencialmente constitucional (como v.g., a constitucionalização do direito à saúde) ou financeira (normas infra-constitucionais de organização das leis orçamentárias ou de arrecadação de tributo vinculado à saúde) para trazer à tona assunto financeiro-constitucional ou constitucional-financeiro (a instituição de um gasto mínimo para a saúde, estabelecido constitucionalmente, é um exemplo desse tipo de norma). (6)

Noutra perspectiva, em vista daquilo que se pretende assegurar - os direitos fundamentais e as garantias que Ihe são correlatas - e da forma como procederá à efetivação, surge a necessidade de se correlacionar, proporcionalmente, as receitas tributárias e as despesas com políticas públicas, em virtude do pacto fundante do Estado. A CRFB (1) estabelece a lógica entre meios e fins de que o Estado dispõe para atingir os fins perseguidos.

\section{Direito fundamental à saúde}

No Brasil, ao contrário do que se noticia em outras experiências jurídicas do direito comparado como, por exemplo, o caso da América do Norte, onde o direito à saúde não é considerado direito fundamental, (7) a CRFB enuncia expressamente o direito à saúde.

A instituição do SUS corporifica e caracteriza a política pública de saúde, conforme dedicação do art. 198, que, integrando uma rede, obedecerá às seguintes regras gerais: regionalização; hierarquização; descentralização, com direção única em cada esfera do 
governo; atendimento integral, com prioridade para atividades preventivas; e gestão democrática com controle social (1).

Em que pese não constar enumerado no rol do art. 5ํ da CRFB, o direito à saúde é notoriamente reconhecido pela ampla doutrina e jurisprudência dos Tribunais Superiores direito social fundamental, dado que, dentre uma das razões que se poderia apontar, caso não fosse assegurado o próprio direito à vida - este sim, constante expressamente do caput da norma mencionada - restaria malferido, já que "[...] representa consequência constitucional indissociável do direito à vida" (8).

Trata-se, em outros termos, de direito que se refere à dignidade da pessoa humana, compondo núcleo intangível do sistema constitucional, tanto que compõe o rol de cláusulas pétreas (9).

Desse modo, a lógica é que se aplique ao direito à saúde, considerando-o incurso no direito à vida, a norma constitucional que lhe garante aplicação imediata (art. $5^{\circ}, \S 1^{\circ}$ da CRFB) (8).

Ademais, as regras que constam dos artigos $6^{\circ}$ e 196 da CRFB voltam-se a todos os entes políticos que integram a organização federativa do Estado brasileiro e, em que pese a defesa de sua natureza programática por autorizada doutrina.

Nesse sentido, Silva (10), em sua obra Aplicabilidade das normas constitucionais, defendeu que "A saúde é [...] dever do Estado [...] aí, não impõe propriamente uma obrigação jurídica, mas traduz um princípio, segundo o qual a saúde e o desporto para todos e cada um se incluem entre os fins estatais, e deve ser atendido. Sente-se, por isso, que as prescrições têm eficácia reduzida [...]".

Entretanto, não se admite a classificação deste direito como uma norma que meramente estabelece metas a serem alcançadas indefinidamente pelo Poder Público. Se assim fosse, todas as garantias inerentes a esse direito seriam uma legislação simbólica, no sentido preconizado por Neves (11), o que seria inadmissível numa leitura sistemática da Constituição Federal, que prevê diversos instrumentos de efetivação desse direito. Para o autor, a legislação simbólica é aquela que sofre de um déficit de concretização normativa, sendo incapaz de impor condutas, pois reflete um papel político-ideológico.

Portanto, as normas constitucionais que preveem o direito à saúde têm aplicabilidade imediata, conferindo posições jurídicas individuais e coletivas plenamente sindicáveis judicial e administrativamente. Isso autoriza a conclusão pela existência de uma cláusula de 
vedação ao retrocesso no regime jurídico atinente aos direitos sociais, especialmente no tocante ao direito à saúde, assunto que será explorado adiante.

\section{Implementação progressiva e vedação ao retrocesso}

Nos termos dispostos no artigo 196 da CRFB (1), sob a perspectiva específica da expressão a saúde é direito de todos, extrai-se dupla acepção: uma subjetiva, uma vez que qualquer sujeito poderá exigir o respectivo acesso universal e gratuito às ações e aos serviços públicos de saúde, inclusive judicialmente; e outra objetiva, que impõe o dever ao Estado de promovê-la mediante políticas sociais e econômicas (12).

Essa bivalência trata de uma característica da proteção dos direitos sociais (incluída a saúde), econômicos e culturais, expressos no reconhecimento jurídico da progressividade, isto é, o grau de reconhecimento jurídico na sua efetiva realização - estágio de juridificação do Estado social -, caractere que merece melhor análise sob o espectro da Carta Maior (13).

A CRFB, nos artigos 1ำ IV, e 3ํㅡㄴ III e IV, conforma o Estado Democrático de Direito no país, cujos alicerces são "os valores sociais do trabalho e da livre iniciativa"; ao lado disso, traça os fins de "erradicar a pobreza e a marginalização e reduzir as desigualdades sociais e regionais; promover o bem de todos, sem preconceitos de origem, raça, sexo, cor, idade, outras formas de discriminação" (1).

Em seguida, o constituinte elenca largo grupo de direitos e deveres individuais e coletivos. Além disso, ao dispor sobre os princípios gerais da ordem econômica, consigna a finalidade de "assegurar a todos existência digna, conforme os ditames da justiça social" (13).

Entrementes, trata-se de arranjo jurídico-constitucional típico do que se convencionou, genericamente, denominar de estado social ou estado de direito democrático e social (13). Apesar de a CRFB não mencionar tal expressão/princípio, ela se projeta nos “objetivos constitucionais gerais (art. $3^{\circ}$ ), nos princípios da ordem econômica (art. 170), nos objetivos da política urbana (art. 182), nas definições dos direitos à saúde (art. 196) e à educação (art. 205) e no planejamento educacional (art. 214), entre outros" (1).

Reforça essa noção a disposição contida no Pacto Internacional sobre Direitos Econômicos, Sociais e Culturais (Pidesc), internalizado por meio do Decreto nํ591, de 1992. Confira-se: 
Art. 2․ 1. Cada Estado-parte no presente Pacto compromete-se a adotar medidas, tanto por esforço próprio como pela assistência e cooperação internacionais, principalmente nos planos econômico e técnico, até o máximo de seus recursos disponíveis, que visem assegurar, progressivamente, por todos os meios apropriados, o pleno exercício dos direitos reconhecidos no presente Pacto, incluindo, em particular, a adoção de medidas legislativas. (14)

$\mathrm{Na}$ esteira do pensamento dos professores Pinto e Ximenes (13), o Pidesc, exemplifica a juridificação da permanência do progresso social e econômico, instrumentalizado pelo dever sempre latente de se atrelar todos os recursos disponíveis à realização dos direitos sociais. Confira-se:

Portanto, enquanto a progressividade diz respeito ao objetivo de máxima realização dos direitos sociais, há obrigações imediatas e inadiáveis, como a adoção permanente de medidas, a aplicação do máximo de recursos disponíveis e a não retroatividade. [...] Permite também colocar em questão a própria noção de "recursos disponíveis" diante de decisões em matéria de política fiscal e tributária que venham a restringir a destinação orçamentária necessária à realização prioritária dos direitos fundamentais. (13)

Todos esses elementos convergem para a aceitação da existência da cláusula da vedação ao retrocesso que o impede em matéria de direitos sociais, ou seja, é uma barreira jurídica às limitações fáticas inerentes aos direitos prestacionais.

Os parâmetros a serem considerados para concluir se há ou não retrocesso são as medidas já levadas a efeito pelo Poder Público, ou seja, as políticas públicas implementadas, instituições e até mesmo leis existentes que, de alguma maneira, consolidem os direitos sociais.

Consequência dessa cláusula é também o dever de maximização da efetividade de direitos sociais, ou seja, as ações governamentais devem, com o passar do tempo, criar um cenário capaz de dispensar mais e mais prestações materiais subjacentes aos direitos sociais. Isso ganha especial relevo no direito à saúde, cujos contornos gerais foram definidos constitucionalmente.

No Pidesc, esse ideário está expresso no artigo 12: "1. Os Estados Partes do presente Pacto reconhecem o direito de toda pessoa de desfrutar o mais elevado nível possível de saúde física e mental" (14).

O princípio da dignidade da pessoa humana, fundamento da República Federativa do Brasil, por sua vez, impõe aos poderes públicos o dever de guiar suas ações rumo à garantia da justiça social e, impreterivelmente, da garantia do mínimo existencial aos cidadãos. 
Por fim, a não retroatividade aludida, ou princípio da vedação do retrocesso, vem em socorro da segurança jurídica na esfera social. Em vista disso, veda-se a subtração de direitos fundamentais por meio da revogação de normas ou políticas públicas garantidoras.

\section{Regime fiscal de financiamento das ações e serviços públicos de saúde}

Contextualizando o tema à realidade brasileira, noticia-se que o estabelecimento de pisos de financiamento, bem como a vinculação de receitas orçamentárias, são questões que se configuram como objeto de intensos embates desde o ano de 1990, consideradas as crises financeiras que assolaram o País e que ressoaram diretamente no custeio de ASPS (15).

Nesse contexto, o financiamento do SUS passou a fazer parte da agenda decisória, o que resultou na promulgação da EC n² 29/2000 que, por sua vez, alterou o artigo 198 da CRFB, incluindo nele uma base de cálculo para a aplicação mínima em ações e serviços públicos de saúde.

Por seu turno, o art. 77 dos Atos das Disposições Constitucionais Transitórias (ADCT) fixou percentuais mínimos de aplicação nas ASPS pelos entes federativos (1). Sobre as finalidades principais da EC em foco, pode-se afirmar que:

[...] foi editada a Emenda Constitucional no 29 que trouxe diversas alterações no SUS, baseadas em duas claras intenções: explicitar a competência de todos os entes para a promoção dos serviços de saúde, garantindo maior nível de investimentos e, por outro lado, diminuir progressivamente as desigualdades regionais. (16)

Nos termos dispostos pela EC № 29, a União deveria, no ano 2000, aplicar montante de valor mínimo superior ao empenhado em 1999, com correção de 5\% (cinco por cento). Nos anos seguintes, o valor mínimo destinado seria o empenhado no ano anterior, corrigido, por sua vez, pela variação do produto interno bruto (PIB) (17) do país. Este regramento foi mantido pela Lei Complementar nำ141/2012 (18) e alterado pela EC nำ 86/2015.

Para os estados da Federação foi estabelecido que deveriam carrear à saúde pelo menos $12 \%$ (doze por cento) do que se arrecadou em impostos estaduais (ICMS, ITCM, IPVA) somado às transferências constitucionais, subtraindo-se, destas últimas, as parcelas destinadas aos respectivos municípios. 
Já os municípios deveriam aplicar em ASPS no mínimo 15\% (quinze por cento) da arrecadação de seus impostos (IPTU, ITBI e ISS) somado ao montante percebido à título de transferências constitucionais efetuadas pelos entes maiores.

Resumindo os resultados do financiamento do SUS pelas três esferas do governo de 2003 a 2007, constatou-se que:

i) principalmente em decorrência da $E C \mathrm{n}^{\circ} 29$, houve crescimento real do gasto em ASPS nas três esferas de governo, sendo que, entre 2003 e 2014, este foi contínuo; ii) o aumento dos gastos foi mais pronunciado no caso dos estados, do Distrito Federal e dos municípios, até porque essas UFs partiram de níveis mais baixos de comprometimento; e iii) isso levou a uma alteração significativa na participação das diferentes esferas no financiamento do SUS. (17)

Em 2015 esse cenário foi alterado em razão do advento da EC n 86/2015. Para a União, alterou-se o método de cálculo do gasto mínimo com ASPS, bem como a base de cálculo que incidiria, passando-se a vincular destinação mínima à porcentagem da receita corrente líquida (RCL), e de maneira progressiva nos seguintes índices: $13,2 \%$ da RCL, em 2016; 13,7\%, em 2017; 14,2\%, em 2018; 14,7\%, em 2019; e 15,0\%, em 2020 (19).

Ressalte-se que o ministro Ricardo Lewandowski, do Supremo Tribunal Federal (STF), deferiu liminar na Ação Direta de Inconstitucionalidade (ADI) 5.595 (20) para suspender a eficácia dos artigos $2^{\circ}$ e $3^{\circ}$ da EC nํ 86/2015 (Emenda do Orçamento Impositivo), que tratam da área de saúde.

\section{Principais aspectos do novo regime fiscal - EC no 95/2016}

O Congresso Nacional promulgou em 15 de dezembro de 2016 a EC no 95 (2), que estabeleceu o novo regime fiscal, cuja principal medida, segundo própria narrativa constante da exposição de motivos do projeto, se refere à "contenção de gastos com políticas públicas", afiançando que promoveria a redução da dívida. Isso, por sua vez, resultaria em crescimento econômico.

Excluído o quanto se aloca ao pagamento de juros da dívida pública, a EC nº 95/2016, especificamente no art. 107, ADCT, congelou os gastos públicos primários pelos próximos vinte exercícios financeiros, estabelecendo teto máximo que somente será corrigido monetariamente de acordo com a inflação do ano anterior, segundo o Índice de Preços ao Consumidor Amplo (IPCA). 
A expressão gastos primários, também conhecida como despesa não financeira, corresponde ao conjunto de gastos que viabilizam a oferta de serviços públicos à população (21).

No que toca singularmente ao financiamento da saúde, conforme nova redação do art. 110 do ADCT, fixou-se que:

[...] na vigência do Novo Regime Fiscal, as aplicações mínimas em ações e serviços públicos de saúde e em manutenção e desenvolvimento do ensino equivalerão: I - no exercício de 2017, às aplicações mínimas calculadas nos termos do inciso I do $\S 2^{\circ}$ do art. 198 e do caput do art. 212, da Constituição Federal; e II - nos exercícios posteriores, aos valores calculados para as aplicações mínimas do exercício imediatamente anterior, corrigidos na forma estabelecida pelo inciso II do $\S 1^{\circ}$ do art. 107 deste Ato das Disposições Constitucionais Transitórias. (2)

Destaque-se a necessidade de uma avaliação qualitativa dessa reforma constitucional, uma vez que uma leitura crua dos dados pode induzir a conclusões equivocadas.

É o caso do relatório de autoria do Tribunal de Contas da União (TCU) colacionado aos memoriais apresentados pela Advocacia Geral da União (AGU) por ocasião da ADI 5.595. Esse relatório demonstra que, de fato, não houve redução aquém do piso constitucional com os gastos em ASPS por parte da União. Ao contrário, mostra-se que

[...] após a promulgação da EC no $86 / 2015$, houve um crescimento efetivo de $6,18 \%$ nos valores aplicados pela União no exercício financeiro subsequente, ou seja, no ano de 2016. Em 2016 a União aplicou mais de 106 bilhões de reais, traduzindo uma elevação de mais de 6 bilhões em relação ao ano anterior, quando ainda em vigor a sistemática anterior da Lei Complementar no 141/2012. O crescimento se manteve nos anos de 2017 e 2018. (20)

Segundo o relatório, em 2017, a União aplicou $R \$ 114.700,61$ (equivalente a 15,77\% da $\mathrm{RCL}$ ); e, em 2018, $\mathrm{R} \$ 116.820,88$ (equivalente a $14,51 \%$ da $\mathrm{RCL}$ ) (20).

Contudo, esses dados têm que ser analisados juntamente com o histórico déficit de financiamento do SUS, bem como a baixa quantia gasta per capita relativamente às ASPS.

Isso significa que não havia, anteriormente à EC no 95/2016, financiamento suficiente para fazer cumprir os mandamentos de universalidade e integralidade do SUS. Esse cenário será agravado pelo regime de gastos promulgado pela União.

Dessa maneira, efeito imediato no Novo Regime Fiscal é de suspensão da normatividade do inciso I do $\S 2^{\circ}$ do art. 198 e do caput do art. 212 da CRFB (1), a partir do 
exercício de 2018 e por vinte anos, devendo a União adotar o mesmo piso vigente em 2017 para a saúde e para a educação, reajustado, ano a ano, apenas pela inflação do período, ainda que haja incremento na arrecadação.

Quanto aos efeitos relativamente mediatos, leia-se a repercussão no custeio da ASPS durante as duas décadas, projeta-se desinvestimento massivo do SUS com as novas regras, considerando diversos contextos macroeconômicos, cujas consequências, resumidamente, se expressarão em:

Privação de recursos em vista das regras de vinculação previstas pelas EC no 29/2000 e $86 / 2015$

O estudo levado a cabo pelo Instituto de Pesquisa Econômica Aplicada (Ipea) precipita o cenário, hipoteticamente, caso a EC ํㅜ 95/16 vigesse desde 2003, tendo revelado que o financiamento do SUS cairia $42,1 \%$ do que efetivamente fora aplicado, o que, expresso em reais, equivaleria a $R \$ 257$ bilhões (22).

\section{Redução do gasto per capita com saúde}

Não se descuida do gasto com saúde per capita, pois, se o piso de gastos permanecer o mesmo, haverá regressividade (e não mero congelamento) em relação à população que tende a crescer e envelhecer.

Conforme projeção do Instituto Brasileiro de Geografia e Estatística (IBGE), a população brasileira, em 2036, terá 20 milhões de pessoas a mais do que se contabiliza hoje (226 milhões) (23). Ainda, atualmente, 12\% da população tem mais de 60 anos, em 2036, serão $21,5 \%(15)$.

Em 2016, a União previu em seu orçamento a aplicação de $R$ \$ 519/pessoa; levando em conta o incremento da população, vinte anos após a vigência do novo regime fiscal, os mesmos gastos per capita com saúde vão se reduzir a $R \$ 411 /$ pessoa (15).

Discricionariedade dos gestores de carrearem mais recursos em ASPS mesmo se houver incremento da economia interna

Assim estabelecido, e conforme dados sistematizados por Pedro Rossi e Esther Dweck (24), supondo que o país cresça economicamente à taxa média de 2,5/ano, o piso de gastos com saúde corresponderia a 12\% da RCL, em 2026; e apenas a 9,4\% após dez anos. 
Com isso, ao longo do tempo, a tendência é de que a falta de crescimento real em tais pisos de custeio implique percentuais de aplicação anuais, proporcionalmente, muito inferiores aos definidos no texto da CF88. A estagnação em valores reais, portanto, da despesa primária global da União e, sobretudo, dos deveres de gasto mínimo em saúde e educação contida nesse teto será tão mais destacada quanto maior for a expansão da arrecadação, em cenário de retomada da atividade econômica do país, ao longo dos 20 anos nos quais a Emenda vigorará. (24).

Noutro cenário, considerando que o PIB cresça 2,0\% ao ano, estima-se que a redução de recursos federais para a saúde será de $R \$ 415$ bilhões (25).

Houve quem argumentasse, inclusive assim fora motivada a PEC correspondente, que os administradores não se atrelariam ao mínimo, pois se trata de piso, podendo gastar com saúde e educação valores superiores a ele. Todavia, tal consideração é falaciosa, ou desavisada, porque

[o] teto de gastos primários totais levará necessariamente à compressão dos gastos com saúde e educação, e isso porque ignora que, dentro os gastos primários congelados, alocam-se igualmente o que se investe em previdência e assistência social, fiscalização administração federal, em suma, gastos com a estruturação e manutenção do Estado e serviços (13).

Desse modo, para que se aplicasse mais em saúde e educação, em montantes além do piso, haveria de se redirecionar recursos de outros setores igualmente submetidos ao teto, "[...] numa disputa fratricida entre diversas áreas de políticas públicas, tendente a prejudicar todas elas" (13).

Além da argumentação jurídica, não se olvida que o contexto é de indisponibilidade de recursos públicos, de modo que o estímulo imediato à atividade econômica será priorizado, ao contrário da saúde, cujos resultados, ao menos os econômicos, não são aferíveis de imediato.

Ademais, as despesas qualificadas também como obrigatórias, que tendem a crescer (destaca-se as previdenciárias), serão profícuas em igualmente comprimir as despesas primárias, atingindo sobremaneira as discricionárias, nas quais se inserem as que se destinam ao custeio da máquina administrativa e os investimentos públicos.

Assim, ao longo das próximas décadas, mostra-se de difícil implementação a tese defendida pelo Governo de que as despesas em educação não serão reduzidas, mas poderão ser acrescidas, por definição do Congresso Nacional, desde que haja remanejamento de recursos de outras áreas (26). 
ASPS serão mais inacessíveis à população

A EC no 95/2016 já é sentida no financiamento federal das ASPS e ecoa no Orçamento do Ministério da Saúde para 2019, com a redução da capacidade de empenho. A referida programação foi reprovada pelo Conselho Nacional de Saúde (CNS), por meio da Resolução no 611, de 13/12/2018 (27).

No ano de 2018, o valor percentual sobre a $R C L$ foi de $13,9 \%$, diminuindo em $R \$ 4,2$ bilhões de seu valor real em relação aos 15\% da RCL. Somando a perda de 2018 com a de 2019, são $R \$ 9,7$ bilhões retirados da saúde em dois anos (28).

Como a correção da inflação não tem o condão de acrescer recursos, tampouco de corrigir seu custo econômico em acordo com a realidade do mercado da saúde, as perdas serão cumulativas pelas causas apontadas, somadas às necessidades não atendidas, ainda, pelo SUS, que sempre se mostrou insuficiente às necessidades das pessoas. Há estudos técnicos que despontam as ineficiências do SUS, notadamente na área da atenção especializada e hospitalar. Não é outra a conclusão a que chegaram os pesquisadores do Ipea:

\begin{abstract}
Pelo exposto nesta Nota Técnica, fica claro que a PEC 241 impactará negativamente o financiamento e a garantia do direito à saúde no Brasil. Congelar o gasto em valores de 2016, por vinte anos, parte do pressuposto equivocado de que os recursos públicos para a saúde já estão em níveis adequados para a garantia do acesso aos bens e serviços de saúde. O congelamento não garantirá sequer o mesmo grau de acesso e qualidade dos bens e serviços à população brasileira ao longo desse período, uma vez que a população aumentará e envelhecerá de forma acelerada. Assim, o número de idosos terá dobrado em vinte anos, o que ampliará a demanda e os custos do SUS. [...] Como o Brasil é um dos países mais desiguais do mundo, a redução do gasto com saúde e dos gastos com políticas sociais, de uma forma geral, afetará os grupos sociais mais vulneráveis, contribuindo para o aumento das desigualdades sociais e para a não efetivação do direito à saúde no país [...]. (25)
\end{abstract}

\title{
Inconstitucionalidade da EC no 95/2016 frente à garantia constitucional de
}

\section{financiamento adequado da saúde}

A par de todos os dados expostos, entende-se que o grande alvo da mudança causada, mesmo tratando-se da única medida em toda a emenda e com relevância constitucional, seja a desvinculação das receitas destinadas à saúde e à educação em proporção com a arrecadação da União, sistema vigente por quase duas décadas. Tanto é assim que, não fosse este ponto específico de que consta em norma constitucional, todas 
as demais regras atinentes ao contingenciamento de gastos públicos poderiam ser regulamentadas via normas infraconstitucionais. Com efeito, a política de austeridade se "entrincheira" no corpo da CRFB (24).

A partir de uma "compreensão integradora sobre as garantias fundamentais" (29), precisamente a fim de proteger o direito fundamental à saúde e, diga-se de passagem, igualmente o direito fundamental à educação, o constituinte originário fez incluir no texto constitucional os pisos previstos no inciso I do $\S 2^{\circ}$ do art. 198 e no caput do art. 212, ambos da CRFB, bem como regras que vinculassem o respectivo financiamento ao crescimento econômico do País.

Não se descura que, na verdade, há uma série de dispositivos constitucionais imbricados em torno da "primazia fiscal dos direitos fundamentais" voltados à realização dos objetivos constitucionais (30).

Trata-se, em verdade, de genuína garantia fundamental que não se confunde com os direitos igualmente fundamentais e correlatos, pois não tutelam imediatamente direitos subjetivos, nada obstante sua previsão ser condição de concretude destes no mundo empírico.

Ora, não fosse o estabelecimento de pisos de gastos com saúde e outras garantias, as normas positivas perderiam (perderam) de fato sua aptidão à eficácia. Portanto, a CRFB não se ateve a declarar direitos sociais, mas previu também os recursos de financiamento da ação estatal, reconhecendo seu caráter prestacional (31).

As normas de custeio, ao lado outras como o art. 34, VII, "e", art. 35, art. 160, parágrafo único, inciso II, todos da CRFB, corporificam um sistema que se integra, destinado a tutelar o financiamento suficiente e progressivo dos direitos fundamentais, notadamente os direitos sociais. Esse conjunto, a que se dá o nome de microssistema de financiamento adequado (30), opera como verdadeiro

[...] eixo dirigente e finalístico dos orçamentos públicos no país, forte o bastante para justificar a criação de tributos com destinação específica à seguridade social - contribuições sociais (CF 88, art. 149 e 195) - e estabelecer uma exceção à regra geral de não vinculação de impostos (art. 167, IV), em favor do direito à educação (art. 212). (13)

A partir desses elementos, reafirma-se que a CRFB, afora as inovações trazidas ao ponto pela EC no 95/2016, garante o direito à saúde da população em sua dimensão objetiva, por meio do microssistema de tutela do custeio suficiente e progressivo dos direitos 
fundamentais a que se aludiu, "[...] compreendido como instrumento de contenção do retrocesso e de proteção da estabilidade jurídica e da progressividade fiscal do financiamento dos direitos fundamentais, para que seja alcançada a finalidade da sua máxima e progressiva eficácia" (30).

Sobre a correlação entre os direitos e as garantias fundamentais erigidas constitucionalmente, um caso que consta na jurisprudência do Supremo Tribunal Federal e ilustra esse entendimento, foi o julgamento acerca do direito à assistência judiciária (artigo 5으, LXXIV).

Concluiu-se que sua materialização pressupunha autonomia administrativa e financeira do órgão responsável pela representação judicial, a Defensoria Pública. Isto é, associou-se o direito fundamental que consta no artigo 5ㄴ, LXXIV, ao arranjo institucional do artigo 134 que lhe permita, sob o fundamento de "direito a ter direitos" (29).

Pinto (29) traça paralelo com o "direito a ter direitos", aludido com a estrutura constitucional do piso de custeio da saúde, tratando-o como o "direito a ter o custeio progressivo e suficiente de direitos”. Quer dizer, as vinculações orçamentárias dos artigos 198 e 212 são garantias fundamentais que instrumentalizam a eficácia do direito fundamental à saúde em seu núcleo, o que, por sua vez, "[...] expressam conteúdo impostergável e incomprimível do postulado da dignidade da pessoa humana".

Merece destaque a medida cautelar deferida, nos autos da ADI 5.595, pelo ministro Ricardo Lewandowski, em que se discute a constitucionalidade do artigo $2^{\circ}$ da Emenda 86/2015, bem anotando que

[...] a ocorrência de reforma constitucional que vise ao aprimoramento dos direitos e garantias fundamentais é medida desejável de atualização dos fins e preceitos da CF, mas alterações que impliquem retrocesso no estágio de proteção por eles alcançado não são admissíveis, ainda que a pretexto de limites orçamentário-financeiros. (20)

Reconhecido, pois, "direito a ter o custeio adequado de direitos". Aliás, as disposições da CRFB, que tocam o mínimo a ser aplicado na área da saúde, e que atrela todos os entes que compõem a Federação,

[...] integram o assim chamado núcleo essencial dos dois direitos humanos e fundamentais correspondentes, o direito à saúde e o direito à educação. Tal exegese, em linhas gerais, prende-se ao fato de que mediante tais regras impositivas de gasto público mínimo o constituinte erigiu os direitos à saúde e à educação a uma posição preferencial no âmbito do conjunto dos direitos 
sociais, numa evidente aposta num modelo de desenvolvimento humano e social aderente a uma concepção de dignidade da pessoa humana que exige a satisfação do assim chamado mínimo existencial sociocultural, de modo a assegurar uma cidadania efetiva e inclusiva. (32)

Voltando à EC no 95/2016, verifica-se que ela torna dificulta imensamente qualquer melhora no custeio da saúde e educação públicas no Brasil, pelo contrário, abre-se espaço para o sucateamento dessas áreas e para a eliminação de seu caráter universal. Como bem afirmam Funcia e Santos (28), "assim sendo, o SUS passa a enfrentar, ao lado de seu subfinanciamento de 30 anos, um processo crescente e contínuo de desfinanciamento, a partir de 2017, em decorrência de um ajuste fiscal que asfixia direitos fundamentais em sua concretude".

Comparato, em análise, à época, da então PEC que culminaria na EC nํ 95/2016, concluiu que:

[...] o regime de vinculação de recursos obrigatórios para ações e serviços públicos de saúde e manutenção e desenvolvimento do ensino tem sido o mais exitoso instrumento de efetividade de tais direitos, ademais de evidenciar a posição preferencial ocupada pela educação e pela saúde na arquitetura constitucional. Considerando que nada há de mais prioritário nos orçamentos públicos que tal desiderato constitucional, sob pena de frustração da própria razão de ser do Estado e do pacto social que ele encerra, resta evidente que a Emenda Constitucional no 95 viola frontalmente o art. 60, § 4º, IV da Constituição de 1988, ao prever reajuste fiscal que tende a suprimir direitos sociais, posto que afronta o mecanismo de financiamento. (33)

A EC no 95/2016 afronta o conteúdo material de regras constitucionais e infraconstitucionais de amparo e proteção a direitos fundamentais, sobretudo em vista da dimensão da aplicabilidade do princípio da proibição do retrocesso social. Isso descerra a possibilidade de se arguir a inconstitucionalidade de normas, em forma de legislação ou de emenda, que impeçam, suprimam ou restrinjam direito fundamental reconhecido pelo microssistema protetivo.

Foi justamente 0 que se deu. Foram impetradas ações diretas de inconstitucionalidade (ADI n 5.633, ADI n 5.643, DI n 5.655, ADI n 5.680, ADI n 5.715, ADI no 5.734) contra a EC no 95/2016 sob o fundamento, presente na totalidade, de que fere os núcleos essenciais do direito à saúde e à educação ao lhes solaparem a garantia de recursos orçamentários para a sua sustentação, ou por, como se defende, malferir a garantia constitucional de financiamento adequado. 
A procuradora-geral da República, Raquel Dodge (34), manifestou-se nas ações contrárias à Emenda Constitucional no 95/16, no sentido de que: "[...] não atinge o núcleo essencial dos direitos fundamentais à saúde e à educação, porque não elimina ou esvazia nenhum direito fundamental"; além disso, entendeu que

[...] outro questionamento das ações é a ofensa à cláusula pétrea dos direitos e garantias individuais. Os autores das ações alegam que as restrições orçamentárias impõem retrocesso no que tange à prestação de direitos sociais. [...] as normas impugnadas não são vocacionadas a abolir ou reduzir em excesso o regime de proteção dos direitos fundamentais porque mantêm, como parâmetro para a fixação dos gastos futuros, o total de despesas efetivadas no exercício de 2017, e garantem a correção de acordo com o IPCA. (34)

Vale anotar que a Corte Suprema já sinalizou no sentido da inconstitucionalidade da desvinculação dos gastos com saúde e educação do montante de receitas arrecadado. Ao conceder medida cautelar na ADI nº 6.129 - impetrada contra Emendas à Constituição do Estado de Goiás que objetivavam implantar um Novo Regime Fiscal no Estado -, a Corte assim se manifestou:

\footnotetext{
[...] ao suspender a exigência de atrelamento, em determinado exercício fiscal, à receita efetivamente arrecadada, dos gastos estaduais com "ações e serviços públicos de saúde" e "manutenção e desenvolvimento do ensino", limitando-os ao montante correspondente às despesas do exercício anterior "corrigidas pela variação do IPCA ou da RCL", o art. 45, I, da Emenda Constitucional 54/2017 de Goiás promoveu, pelo prazo de dez anos, desvinculação à margem do figurino constitucional (CF, arts. 198, § º , II, e 212, caput). Uma vez atado o teto de gastos com saúde e educação ao total de despesas do exercício anterior, desobriga-se a Administração de promover acréscimo dos valores direcionados às áreas caso verificado incremento de receita, devendo obediência apenas ao novo limite criado, e não mais ao piso constitucionalmente estabelecido. (35)
}

Em conclusão, excluiu-se "qualquer interpretação que venha a resultar na aplicação de recursos nas ações e serviços públicos de saúde e na manutenção e desenvolvimento do ensino em montante inferior ao mínimo previsto em sede constitucional” (35).

Atinente ao tema de ativismo judicial dos direitos sociais, para Bonavides (36) aqueles direitos, consagrados como fundamentais, exigem necessariamente a proteção do Poder Judiciário em face de normas que visem a deteriorar o núcleo basilar desses direitos.

Considera-se que as ADls têm o tom de oferecer a tutela adequada aos direitos sociais, em especial o direito à saúde, isto é, não ignoram o caráter coletivo que possuem (37). Quer dizer, pretendem salvaguardar o direito à saúde sob o viés de política pública, em 
sua perspectiva objetiva e não como um "direito individual, cujo cumprimento pode ser exigido diretamente por meio de uma ação judicial" (38).

E, sobretudo, trata-se de oportunidade de se reverter o propalado "estado de sítio fiscal", conforme os dados e projeções trazidos à discussão, sempre em vista de que

[...] a salvaguarda da vida é, de regra, prioritária em relação à reserva do possível, ainda que tendo consequência (ou mesmo pressupondo) eventual comprometimento de outras demandas ou eventuais ajustes orçamentários, o que, à evidência, somente poderá ser aferido definitivamente no caso concreto. (39)

A partir desses elementos conclui-se que a $E C$ n- 95/2016 não garante sequer uma estabilidade ao custeio do SUS, é dizer, não impõe a manutenção do gasto com ASPS nos mesmos patamares dos anos anteriores à sua promulgação.

Além disso, mesmo que mantivesse os gastos com ASPS nos mesmos patamares dos anos anteriores - o que não faz -, esse fato, isoladamente, já conduziria a uma regressividade no financiamento do Sistema. Isso, pois, a tendência nos anos seguintes é o aumento da demanda por prestações de saúde em razão do crescimento e do envelhecimento da população.

Assim, a Emenda conduz a um cenário no qual o investimento em saúde pública será inversamente proporcional ao aumento da demanda.

Esses dados convergem para a inconstitucionalidade da EC no 95/2016, pois malfere a arquitetura constitucional que permitiria garantir o financiamento adequado da saúde e conduz, assim, a uma precarização da saúde pública brasileira.

\section{Considerações finais}

A Emenda Constitucional no 95 de 2016, é, por tudo o quanto foi descrito, inconciliável com as políticas públicas de saúde nos moldes em que se definem na CRFB, sobretudo sopesados os cânones do SUS, da integralidade e da universalidade, que já não podiam ser assimilados à realidade com os recursos disponíveis de outrora, muito menos com as cifras minguadas pelo novo regime fiscal.

As fronteiras de gasto público estabelecidas pela EC nำ 95/2016 sentenciam a efetividade do direito fundamental à saúde e a garantia de financiamento das ASPS à 
inexequibilidade, subvertendo a lógica de instrumentalidade dos orçamentos e dos recursos públicos em nome de uma suposta austeridade fiscal.

O congelamento dessas despesas por duas décadas representa uma não responsabilização do Estado com a efetivação de direitos sociais, com impactos em uma progressiva e deletéria desvinculação entre a atuação pública no campo social e a dinâmica de crescimento econômico do Brasil. Isso faz com que se questione se a medida de austeridade não significa uma afronta ao próprio Estado Democrático de Direito e Social, presente no pacto fundante que concebeu a Carta Maior.

Diante disso, a proibição de retrocesso social constitui simultaneamente uma garantia constitucional e um direito subjetivo de cada sujeito. Isso significa que as conquistas que envolvem tais direitos não podem ser interrompidas, de modo que, quaisquer meios que tendam a diminuir sua efetivação, tal qual o congelamento dos gastos públicos por duas décadas sem qualquer aumento real, devem ser considerados inconstitucionais.

\section{Referências}

1. Brasil. Constituição da República Federativa do Brasil, 8 de outubro de 1988. Brasília: Senado Federal, 2008.

2. Brasil. Constituição da República Federativa do Brasil. Emenda constitucional n 95, de 15 de dezembro de 2016. Altera o Ato das Disposições Constitucionais Transitórias, para instituir o Novo Regime Fiscal, e dá outras providências. Brasília, 15 dez 2016. Disponível em: http://www.planalto.gov.br/ccivil_03/Constituicao/Emendas/Emc/emc95.htm. [Acesso em 22.abr.2020].

3. Streck LL. Hermenêutica jurídica e(em) crise: uma explicação hermenêutica na construção do direito. 6. ed. Porto Alegre: Livraria do Advogado, 2005.

4. Assunção MC. O orçamento público como instrumento de busca da felicidade. Revista Tributária e de Finanças Públicas. Set./out. 2016, v. 130: 12-14.

5. Brasil. Supremo Tribunal Federal. Medida Cautelar em Ação Direta de Inconstitucionalidade 4048. Requerente: Partido da Social Democracia Brasileira (PSDB). Intimado: Presidente da República. Relator Min. Gilmar Mendes. Brasília - DF, 14 de maio 2008. DJe-157, 22 de agosto de 2008.

6. Carvalho AC. Uma teoria de direito constitucional financeiro e direito orçamentário substantivo no Brasil. In: Conti JM, Scaff FF, organizadores. Orçamentos públicos e direito financeiro. São Paulo: Editora Revista dos Tribunais, 2011. 
7. Faim Filho EG. A judicialização da saúde e seus reflexos orçamentários. In: Conti JM, Scaff FF, organizadores. Orçamentos públicos e direito financeiro. São Paulo: Editora Revista dos Tribunais, 2011.

8. Brasil. Supremo Tribunal Federal. Recurso Extraordinário 271286/RS. Requerentes: Município de Porto Alegre e Estado do Rio Grande do Sul. Requerida: Diná Rosa Vieira. Relator: Min. Celso de Mello. Brasília - DF, 12 de setembro de 2000. DJ 23 de agosto de 2000, p. 52.

9. Mendes GF, Branco PGG. Curso de direito constitucional. 10. ed. São Paulo: Saraiva, 2011.

10. Silva JA. Aplicabilidade das normas constitucionais. 2. ed. São Paulo: RT, 1999.

11. Neves M. A constitucionalização simbólica. São Paulo: Martins Forense, 2007.

12. Pinto EG. Financiamento dos Direitos à Saúde e à Educação: uma perspectiva constitucional. Belo Horizonte: Fórum, 2014.

13. Pinto EG, Ximenes SB. Financiamento dos direitos sociais na constituição de 1988: do "pacto assimétrico" ao "estado de sítio fiscal". Educação \& Sociedade. 2018; v. 39(145):980-1003.Disponível em: http://www.scielo.br/scielo.php?script=sci_arttext\&pid=S010173302018000400980\&lng=en \&nrm=iso. [Acesso em 10.abr.2019].

14. Brasil. Presidência da República. Decreto no 591, de 6 de julho de 1992. Atos Internacionais. Pacto Internacional sobre Direitos Econômicos, Sociais e Culturais. Promulgação. Brasília, 7 jun 1992. Disponível em: http://www.planalto.gov.br/ccivil_03/decreto/1990-1994/d0591.htm [Acesso em 9.jul.2019].

15. Vieira FS, Benevides RPS. Os impactos do novo regime fiscal para o financiamento do sistema único de saúde e para a efetivação do direito à saúde no Brasil. Nota Técnica n. 28. Brasília: Ipea, 2016a. Disponível em: http://repositorio.ipea.gov.br/handle/11058/7270. Acesso em: 10 jul. 2019.

16. Buissa L, Bevilacqua L. Evolução da tributação e o custeio de políticas públicas de saúde no Brasil. Interesse Público - IP. 2018; 20(112): p. 145.

17. Brasil. Instituto Brasileiro de Pesquisa Aplicada (IPEA). Consolidação do gasto com ações e serviços públicos de saúde: trajetória e percalços no período de 2003 a 2017. Texto de Discussão 2439. Brasília: 2018.

18. Brasil. Lei Complementar $\mathrm{n}^{\circ}$ 141, de 13 de janeiro de 2012. Regulamenta o $§ 3$ o do art. 198 da Constituição Federal para dispor sobre os valores mínimos a serem aplicados anualmente pela União, Estados, Distrito Federal e Municípios em ações e serviços públicos de saúde; estabelece os critérios de rateio dos recursos de transferências para a saúde e as normas de fiscalização, avaliação e controle das despesas com saúde nas 3 (três) esferas de governo; revoga dispositivos das Leis nos 8.080 , de 19 de setembro de 
1990, e 8.689, de 27 de julho de 1993; e dá outras providências. Brasília: 16 jan 2012.

Disponível em: http://www.planalto.gov.br/ccivil_03/leis/lcp/lcp141.htm. [Acesso em 22 abr 2020]

19. Brasil. Constituição da República Federativa do Brasil. Emenda Constitucional no 86, de 17 de março de 2015. Altera os arts. 165, 166 e 198 da Constituição Federal, para tornar obrigatória a execução da programação orçamentária que especifica. Brasília: 18 mar 2015. Disponível em:

http://www.planalto.gov.br/ccivil_03/constituicao/Emendas/Emc/emc86.htm. [Acesso em 22 abr 2020].

20. Brasil. Supremo Tribunal Federal. Ação Direta de Inconstitucionalidade 5595. Relator: Min. Ricardo Lewandowski. Brasília, 28 de fevereiro de 2018. Disponível em:

http://stf.jus.br/portal/jurisprudencia/listarJurisprudencia.asp?s1=\%28ADI\%24\%2ESCLA\%2 $\mathrm{E}+\mathrm{E}+5595 \% 2 \mathrm{ENUME} \% 2 \mathrm{E} \% 29+\mathrm{NAO}+\mathrm{S} \% 2 \mathrm{EPRES} \% 2 \mathrm{E} \&$ base=baseMonocraticas\&url=http ://tinyurl.com/yb9az9e8 [Acesso em: 17 jul. 2019].

21. Brasil. Ministério da Economia. Orçamento federal. Disponível em: http://www.orcamentofederal.gov.br/glossario-1/glossario_view?letra=D. [Acesso em 10.jul.2019].

22. Souza TG, Oliveira SM. Nota técnica sobre a PEC 241/2016 e suas repercussões para a saúde. Rio de Janeiro: Defensoria Pública do Estado do Rio de Janeiro; 2016.

23. Brasil. Instituto Brasileiro de Geografia e Estatística (IBGE). Projeção da População do Brasil por sexo e idade: 2000-2060. Disponível em:

https://ww2.ibge.gov.br/home/estatistica/populacao/projecao_da_populacao/2013/default_t ab.shtm [Acesso em 12.jul.2019].

24. Rossi $P$, Dweck E. Impactos do novo regime fiscal na saúde e educação. Cadernos de Saúde Pública. 2016; 32(12): (sem p). Disponível em:

http://www.scielo.br/scielo.php?script=sci_arttext\&pid=S0102311X2016001200501\&lng=en \&nrm=is [Acesso em: 10 jul. 2019].

25. Vieira FS, Benevides RPS. O Direito à Saúde no Brasil em Tempos de Crise Econômica, Ajuste Fiscal e Reforma Implícita do Estado. Revista de Estudos e Pesquisas sobre as Américas, v. 10, n. 3, p. 1-28, $2016 \mathrm{~b}$.

26. Tanno CR. Novo regime fiscal constante da PEC n²41/2016: análise dos Impactos nas políticas educacionais. Estudo Técnico n. 18/2016. Brasília: Câmara dos Deputados/Consultoria de Orçamento e Fiscalização Financeira, 2016.

27. Brasil. Conselho Nacional de Saúde. Resolução 611, de 13 de dezembro de 2018. Disponível em: http://conselho.saude.gov.br/resolucoes/2018/Reso611.pdf [Acesso em: 15 jul. 2019]. 
28. Funcia FR, Santos L. Do subfinanciamento ao desfinanciamento da saúde: descendo as escadas. Revista Domingueira da Saúde. 2019. 4 (sem p.). Disponível em:

http://idisa.org.br/domingueira/domingueira-n-04-janeiro-2019 [Acesso em: 11 jul. 2019].

29. Pinto EG. STF reconhece o "direito a ter o custeio adequado de direitos" na ADI 5.595. Consultor Jurídico. 12 setembro 2017. Disponível em: https://www.conjur.com.br/2017-set12/contas-vista-stf-reconhece-direito-custeio-adequado-direitos-adi-5595 [Acesso em: 10 jul. 2019].

30. Pinto EG. ADCT é o "retrato de Dorian Gray" da Constituição de 1988. Consultor Jurídico. Setembro 2016. Disponível em: https://www.conjur. com.br/2016-set-27/adctretrato-dorian-gray-constituicao-1988 [Acesso em: 17 jul. 2019].

31. Scaff FF. Direito à saúde e os Tribunais. In: Nunes AJA; Scaf FF. Os Tribunais e o direito à saúde. Porto Alegre: Livraria do Advogado, 2011

32. Sarlet IW. Proteção de direito fundamentais diante das emendas (parte 3). Conjur, 10 jun. 2016. Disponível em: https://www.conjur.com.br/2016-jun-10/protecao-direitosfundamentais-diante-emendas-parte [Acesso em 11 jul. 2019].

33. Comparato FK. Financiamento dos direitos à saúde e à educação: mínimos inegociáveis. Conjur, 27 jul. 2016. Disponível em: https://www.conjur.com.br/2016-jul27/financiamento-direitos-saudeeducacaominimos-inegociaveis [Acesso em: 13 jul. 2019].

34. Brasil. Ministério Público Federal. Procuradoria Geral da República. Emenda Constitucional 95/2016 não fere a Carta Magna nem esvazia direitos fundamentais, opina PGR. 13 de novembro de 2018. Disponível em: http://www.mpf.mp.br/pgr/noticiaspgr/emenda-constitucional-95-2016-nao-fere-a-carta-magna-nem-esvazia-direitosfundamentais-opina-pgr. [Acesso em: 13 jul. 2019].

35. Brasil. Supremo Tribunal Federal. Ação Direta de Inconstitucionalidade 6129. Requerente: Procuradora-Geral da República. Intimado: Assembleia Legislativa do Estado de Goiás. Relator: Min. Marco Aurélio. Brasília, 11 de setembro de 2019. Disponível em: https://portal.stf.jus.br/processos/detalhe.asp?incidente $=5691704$ [Acesso em: 20 set. 2019].

36. Bonavides P. Curso de direito constitucional. 11. ed. São Paulo: Malheiros; 2001.

37. Silva VA. O Judiciário e as políticas públicas: entre transformação social e obstáculo à realização dos direitos sociais. In: Souza Neto CP; Sarmento D. Direito sociais: fundamentação, judicialização e direitos sociais em espécies. Rio de Janeiro: Lumen Juris; 2008.

38. Nunes AJA. Os tribunais e o direito à saúde. Texto para comunicação apresentado em Porto Alegre no Congresso Internacional sobre Direito Sanitário, organizado pela Escola de Saúde Pública do Rio Grande do Sul, de 21 a 25 de maio de 2010. 
39. Sarlet IW. Reserva do possível, mínimo existencial e direito à saúde: algumas aproximações. In: Sarlet IW; Timm LB. Direitos fundamentais: orçamento e "reserva do possível". Porto Alegre: Livraria do Advogado Editora; 2008.

\section{Colaboradores}

Todos os autores contribuíram com a concepção, elaboração, redação, revisão e aprovação do artigo.

Como citar este artigo:

Bevilacqua L, Soares FF, Santos JMT. Novo regime fiscal frente à garantia constitucional de financiamento adequado das políticas públicas de saúde. Cadernos Ibero-Americanos de Direito Sanitário. 2020 abr./jun.; 9(2): 74-98.

http://dx.doi.org/10.17566/ciads.v9i2.672 